\title{
Are Neuropsychological Changes Relevant in Subclinical Hypothyroidism?
}

\section{perspectivas}

\author{
Cloyra Almeida \\ MARIO VAISMAN \\ ANTONIO José Leal Costa \\ FABIOLA A.A. REIS \\ VANESKA REUTERS \\ PATRICIA TEIXEIRA \\ MARCIA FERREIRA \\ LETÍCIA B.B. DE M. TEIXEIRA \\ GLÓRIA R.B. DE ARAÚJO \\ MARCO ANTONIO BRASIL
}

Endocrinology Service of the HUCFF-UFRJ (CA \& MV);

Department of Preventive

Medicine and the Collective Health Study Center at the Medical School of the UFRJ

(AJLC); Medical School of the UFRJ (FAAR \& LBBMT); Endocrinology at the UFRJ (VR, PT \& MF); Medical Psychology and Mental Health Service of the HUCFF-UFRJ (GRBA); Department of Psychiatry and Forensic Medicine of the UFRJ (MAB), Rio de Janeiro, RJ.

Recebido em 07/06/06 Revisado em 05/01/07 Aceito em 23/01/07

\section{ABSTRACT}

Introduction: Neuropsychological changes are still controversial in patients with subclinical hypothyroidism (SH). The objective of this study is to assess these changes. Method: Cross-sectional study comparing the results of the neurocognitive evaluation of $65 \mathrm{SH}$ patients and 31 individuals without thyroid disease. Subclinical hypothyroidism was defined as at least two elevated serum TSH levels $(>4 \mu \mathrm{Ul} / \mathrm{ml})$ with normal serum free $\mathrm{T}_{4}$ levels (0.9-1.8 $\left.\mathrm{ng} / \mathrm{dl}\right)$. The participants underwent the following neuropsychological assessment: Buschke's Selective Reminding Procedure, Rey-Osterrieth Complex Figure Test, Warrington's Recognition Memory Test for Words and Faces, and the Vocabulary subtest of the WAIS-R. Results: The groups were similar in regard to mean age, sex and educational level. No neuropsychological change was found in patients with $\mathrm{SH}$ when compared with euthyroid individuals. Conclusion: No difference was observed in the performance of the neuropsychological tests between both groups in regard to the functions studied. (Arq Bras Endocrinol Metab 2007;51/4:606-611)

Keywords: Hypothyroidism; Neuropsychology

\section{RESUMO}

\begin{abstract}
Alterações Neuropsicológicas são Relevantes no Hipotireoidismo Subclínico?

Introdução: Até o presente momento, não se tem confirmação da presença de alterações neuropsicológicas em pacientes com hipotireoidismo subclínico (HS). O objetivo desta pesquisa foi avaliar essas alterações. Método: Estudo seccional comparando os achados neuropsicológicos de 65 pacientes com HS e 31 indivíduos eutireoidianos. HS foi confirmado por duas dosagens plasmáticas elevadas de TSH ( $>4 \mu \mathrm{Ul} / \mathrm{ml}$ ) associadas com dosagem sérica de $\mathrm{T}_{4} \mathrm{~L}$ na faixa da normalidade $(0,9-1,8 \mathrm{ng} / \mathrm{dl})$. Para avaliação neuropsicológica, foram utilizados o procedimento de Buschke, a figura de Rey-Osterrieth, o reconhecimento de palavras e faces de Warrington e o subteste Vocabulário do WAIS-R. Resultados: Os grupos foram similares quanto a idade, sexo e nível de escolaridade. Não encontramos alterações neuropsicológicas nos pacientes com HS em comparação ao grupo eutireoidiano. Conclusão: Não foi encontrada nenhuma diferença nos resultados dos testes neuropsicológicos entre os dois grupos em relação às funções estudadas. (Arq Bras Endocrinol Metab 2007;51/4:606-611)
\end{abstract}

Descritores: Hipotireoidismo; Neuropsicologia

EVERAL STUDIES HAVE reported a prevalence of overt hypothyroidism in $\checkmark$ the adult population of $1-2 \%$ and of subclinical hypothyroidism $(\mathrm{SH})$ of $5-10 \%$; women are more frequently affected than men are, at a ratio of $4: 1$. The prevalence of $\mathrm{SH}$ increases with age, reaching $15 \%$ among women older than 50 years, and decreases after the age of 80 years (1). 
In hypothyroidism, the neuropsychological and psychiatric alterations are well known (2-7). Frequently, the psychiatric symptoms are the first to appear in clinical hypothyroidism $(\mathrm{CH})$. Among them, the neurocognitive alterations (memory and concentration difficulty), followed by depression, are the most common and precocious. In the course of the illness, a deficit in attention, abstraction capacity and problem solving ability may occur. The lack of diagnosis can evolve to serious cognitive deficit and dementia (8-10) and, if not treated, become permanent. In SH, the opinions about psychiatric symptoms and neurocognitive alterations are still controversial. There is no indication of how the cognitive profile of $\mathrm{SH}$ patients may be differentiated from that of those with more severe forms (5).

Until the present moment, the studies on the association between $\mathrm{SH}$ and neuropsychological alterations are controversial. Baldini et al. (1997) and Bono et al. (2004) found an association between the $\mathrm{SH}$ and neuropsychological alterations, as for the logical memory, attention, global cognitive functioning and some executive functions. The memory deficit reported by Bono et al. (2004) was related only to age. Jorde et al. (2005), in a population study, using a battery of tests to evaluate attention, visual and verbal memory, intelligence and executive functions, found no difference between patients with $\mathrm{SH}$ and euthyroid individuals. Four studies reported an improvement in the performance of tests assessing the neuropsychological function of patients with $\mathrm{SH}$ when treated with thyroid hormones (Nyström et al., 1988; Jaenschke et al., 1996; Baldini et al., 1997; and Jensowsky et al., 2002), while another study (Jorde et al., 2005) did not find any significant change.

Studies on neuropsychological and behavioral characteristics of patients with $\mathrm{SH}$ found significant deficiencies in the abilities related to memory (Monzani et al., 1993) and logical memory (Baldini et al., 1997). In the total memory coefficient, Baldini et al. (1997) found no significant reduction.

Our study, the first published in Brazil, aimed at assessing the effects of changes in the thyroid hormone levels on neuropsychological functions by comparing the performance of patients with minimum thyroid dysfunction with that of euthyroid individuals.

\section{METHODS}

This is a cross-sectional study that assessed the prevalences of neuropsychological changes in patients with $\mathrm{SH}$, who were referred to the Endocrinology Service of the Clementino Fraga Filho Teaching Hospital of the Federal University of
Rio de Janeiro (HUCFF/ UFRJ). Such prevalences were compared with those of euthyroid individuals.

The criterion for diagnosing $\mathrm{SH}$ was at least two elevated serum TSH levels (normal reference range: 0.4-4.0 $\mu \mathrm{U} / \mathrm{mL}$ ) with a normal free $\mathrm{T}_{4}$ level $(0.8-1.8 \mathrm{ng} / \mathrm{dL})$. Those measurements were taken at the Clinical Pathology and Hormones Laboratory of the HUCFF at two different occasions at least one month apart.

The patients with $\mathrm{SH}$ were of both sexes, with ages ranging from 18 to 65 years and third-grade educational level at least, enabling them to interpret the tests.

The exclusion criteria were as follows: patients with severe chronic diseases that could interfere with the hypothalamus-hypophysis-thyroid axis dynamics; hospitalized patients; patients using drugs that affect thyroid function and thyroid hormone concentrations; patients with TSH levels higher than $20 \mu \mathrm{U} / \mathrm{mL}$, even with normal free $\mathrm{T}_{4}$ levels; and patients diagnosed as psychiatric or requiring psychiatric treatment.

A group of individuals without any thyroid disease and, therefore, with normal TSH levels, meeting the same exclusion criteria, was formed to serve as a control and to be compared with the patients. Those individuals were negative for thyroid peroxidase antibodies (TPOAb) and were homogeneous in regard to the sex, age and educational level distributions.

All participants were selected in the same hospital environment and met all inclusion criteria. They were introduced to the study's protocol, which had been approved by the committee on ethics and research at the HUCFF/UFRJ. They signed the written informed consent and received a copy of it.

On the first medical visit, all participants underwent clinical examination after general and specific anamnesis for physical and psychiatric changes. Signs and symptoms of hypothyroidism were assessed by use of the Zulewski score, which was considered compatible with thyroid dysfunction when $\geq 3$ and normal when $<3$. On that occasion, blood was collected for thyroid hormone ( $\mathrm{TSH}$ and $\mathrm{FT}_{4}$ ) and TPOAb measurements. The neuropsychological tests were performed within 30 days of the initial clinical assessment.

As a result of the existing instruments in the literature, we chose to carry out a pilot study for evaluating which would be the best tool for our research.

\section{Pilot project's tools}

Based on previous studies (2-5), a battery of neuropsychological tests was chosen for the present study comprising the following: a) vocabulary subtest of the revised version of the Wechsler Adult Intelligence Scale (WAIS-R) (verbal cognitive functioning level); b) Buschke's Selective Reminding Procedure (list-learning ability); and c) Rey-Osterrieth complex figure test (visuo-perceptive memory).

\section{Results and conclusion of the pilot project}

The pilot project evidenced the need for a wider evaluation of attention and memory deficits. The tests used in the first battery only pointed to an alteration, but they did not guarantee a difference between patients with and without $\mathrm{SH}$. 
Therefore, a more flexible battery was used to comprehensively evaluate the brain geography, and the Warrington's Recognition Memory Test for Words and Faces (verbal and nonverbal memory) ("Two-Choice Recognition Memory for Words and Faces" - Warrington, 1984) was added to assess memory and attention accuracy.

\section{Neuropsychological assessment tools}

Vocabulary subtest of the revised version of the Wechsler Adult Intelligence Scale (WAIS-R) verbal cognitive functioning level

We used the shortened form comprising the verbal subtest WAIS-R vocabulary, considered a methodologically trustworthy evaluation for cognitive leveling.

It consists of 35 words in sequence of increasing difficulty. The individual is requested to give the meaning of each word in the list.

Each answer scores 2,1 or 0 points, according to the general principles of the manual of instructions. The score is computed during consecutive correct answers up to the answer that precedes a wrong one in a series of five consecutive errors. From then on, correct answers are computed according to the procedure of the test of limits (Sattler, 1990).

Buschke's Selective Reminding Procedure (BUSCHKE, 1973) - storage, evocation-consistent long-term retrieval, random long-term retrieval, intrusions (evocation of words that are not part of a list), late evocation (approximately 30 minutes after the last attempt), and recognition (number of words correctly recognized from the four words presented)

Used to assess the immediate and intermediate auditory and visual memory (capacity of consistent storage).

The test consists of a list of 12 words, six of them being "high-imagery", that is, words with potential to be more easily fixed. The patient must repeat the words in the order he can remember. After each attempt (total of 12), the words not retrieved should be repeated, and the patient should be prompted to repeat them (all) once again.

After a 20-minute break applying other tests, the words should be repeated to the patient and a new attempt made. If the patient is not able to repeat (evoke) the 12 words, a recognition procedure consisting of a multiple-choice format should be added.

Recall of Complex Design (Rey, 1941; Osterrieth, 1944) - performance on copying and evoking a complex figure

Used to assess the visuo-perceptive-motor memory. The patient is requested to copy a complex figure. After a 20 minute break using other instruments of evaluation, the patient is requested to redraw the figure from memory.
Two-Choice Recognition Memory for Words and Faces (Warrington, 1984) - performance on the Warrington's Recognition Memory Test for Words and Faces

Used to assess the visual and spatial memory (test of faces) and the verbal memory (test of words). Initially 50 words are presented to the patient. Immediately after, pairs of words are presented and the patient should recognize the words first presented. The same procedure is repeated, now with 50 black and white facial pictures, which are first presented isolated and, then, in pairs. The patient should recognize the ones first seen.

\section{Statistical analysis}

The statistical analysis of data derived from the battery of neuropsychological tests was performed by using the Statistical Analysis System (SAS). The data underwent multivariate analysis of variance (MANOVA) and subsequent univariate analysis of variance (ANOVAs).

Significance was established at the $5 \%$ level $(\mathrm{p}<0.05)$.

\section{RESULTS}

Sixty-five patients with SH were studied, 61 females (mean age [SD]: 48.1 [10.1] years, range: 24-64), along with 31 euthyroid individuals ( 29 females, mean age [SD]: 42.1 [9.1] years, range: 26-61). The mean age and educational level were not significantly different between both groups (table 1).

Thirty-three $\mathrm{SH}$ patients were positive for TPOAb antibodies. The laboratory characteristics of the participants are shown in table 2 with no significant difference between patients and euthyroid individuals.

In regard to the neuropsychological tests, we found no significant differences between the two groups studied in the cognitive function tests: WAIS$\mathrm{R}$ - Vocabulary; immediate and late verbal memory tests (Buschke's: storage, retrieval, consistent and random long-term retrieval, intrusion, late evocation and recognition tests); Warrington's Recognition Memory Test for Words and Faces; and visuo-perceptive-motor tests (Rey-Osterrieth's figure copying) (table 3).

\section{DISCUSSION}

Up to the present day, studies assessing neuropsychological changes in $\mathrm{SH}$ are scarce. In our opinion, this may be due to the characteristics of the assessments, which are usually long lasting, of difficult application and replication, and require trained personnel. In addition, such assessments are susceptible to social, economic and cultural variables, to age groups and educational level, requiring, therefore, specific tests for 
Table 1. Demographic characteristics of euthyroid individuals (control group) and patients with subclinical hypothyroidism $(\mathrm{SH})$

\begin{tabular}{lcc}
\hline & $\begin{array}{c}\text { Euthyroid } \\
(\mathbf{n = 3 1 )}(\%)\end{array}$ & $\begin{array}{c}\text { SH } \\
(\mathbf{n}=\mathbf{6 5})(\%)\end{array}$ \\
\hline Gender & $2(6 \%)$ & $4(6 \%)$ \\
Male & $29(94 \%)$ & $61(94 \%)$ \\
Female & $42.1 \pm 9.1$ & $48.1 \pm 10.1$ \\
Age & & $19(29.2 \%)$ \\
Education & $9(30 \%)$ & $23(35.44 \%)$ \\
Under $8^{\text {th }}$ grade & $11(35 \%)$ & \\
8-11th grade & & \\
\hline
\end{tabular}

Table 2. Clinical and laboratory characteristics of euthyroid individuals (control group) and patients with subclinical hypothyroidism (SH).

\begin{tabular}{lcc}
\hline & $\begin{array}{c}\text { Euthyroid } \\
(\mathbf{n = 3 1 )}\end{array}$ & $\begin{array}{c}\text { SH } \\
(\mathbf{n = 6 5 )}\end{array}$ \\
$\mathrm{TSH}$ & $1.7 \pm 0.6$ & $8.1 \pm 3.2$ \\
$\mathrm{FT}_{4}$ & $1.2 \pm 0.2$ & $1.1 \pm 0.2$ \\
Clinical Score & $3.2 \pm 1.9$ & $3.2 \pm 1.7$ \\
\hline
\end{tabular}

* no significant difference $(p>0.05)$

Table 3. Assessment of the neuropsychological functions of patients with subclinical hypothyroidism $(\mathrm{SH})$ and euthyroid individuals (control group).

\begin{tabular}{|c|c|c|c|c|}
\hline \multirow{2}{*}{ Neuropsychological tools } & \multicolumn{2}{|c|}{ SH $(n=65)$} & \multicolumn{2}{|c|}{ Control $(n=31)$} \\
\hline & mean & SD & mean & SD \\
\hline \multicolumn{5}{|l|}{ Cognitive function } \\
\hline WAIS-R - Vocabulary & 25.80 & 9.25 & 23.64 & 10.40 \\
\hline \multicolumn{5}{|l|}{ Visuospatial Memory } \\
\hline Rey-Osterrieth's figure - Evocation & 16.03 & 6.29 & 17.14 & 4.92 \\
\hline Warrington - Faces & 44.21 & 4.14 & 45.30 & 3.66 \\
\hline \multicolumn{5}{|l|}{ Immediate and late verbal memory } \\
\hline \multicolumn{5}{|l|}{ Buschke } \\
\hline Storage & 82.38 & 26.09 & 83.09 & 26.72 \\
\hline Retrieval & 88.09 & 20.74 & 85.93 & 22.04 \\
\hline Consistent long-term retrieval & 51.82 & 26.10 & 50.90 & 27.44 \\
\hline Random long-term retrieval evocation & 20.16 & 16.10 & 23.06 & 16.33 \\
\hline Intrusion & 5.06 & 5.03 & 4.96 & 6.54 \\
\hline Late evocation & 7.43 & 2.53 & 6.77 & 2.74 \\
\hline Recognition & 11.44 & 1.11 & 11.29 & 1.13 \\
\hline \multicolumn{5}{|l|}{ Warrington } \\
\hline Evocation & 44.55 & 5.18 & 44.87 & 4.11 \\
\hline \multicolumn{5}{|l|}{ Visuo-perceptive-motor } \\
\hline Rey-Osterrieth's figure - Copy & 29.96 & 5.16 & 28.43 & 4.84 \\
\hline
\end{tabular}

* no significant difference $(p>0.05)$

each sample studied. In eight studies published (1118) with a similar design, 15 different tools were used for the neuropsychological assessment of intellectual level, orientation, attention, memory, and verbal, visuospatial, executive and motor functions.

Due to the lack of a standard neuropsychological assessment, we chose to develop a pilot project with a flexible battery of tools, which were known to the working team and available in our country. In addition, in our opinion, this neuropsychological battery comprised tests adequate for the specific population and evaluated, as widely as possible, the behavioral geography of the brain and the desired neuropsychological functions.
Until the present time, studies about the association between $\mathrm{SH}$ and neuropsychological changes are inconclusive and controversial. Baldini et al. and Bono et al. $(12,13)$ reported an association between $\mathrm{SH}$ and neuropsychological changes in regard to logical memory, attention, global cognitive functioning and some executive functions. On the other hand, the memory deficit reported by Bono et al. (13) was related only to age. However, Jorde et al. (18), using a battery of tests in a population study to assess attention, visual and verbal memory, intelligence and executive functions, found no difference between patients with $\mathrm{SH}$ and euthyroid individuals. 
Four studies (12,15-17) reported an improvement in the performance of tests assessing the neuropsychological function of patients with $\mathrm{SH}$ when treated with thyroid hormones; nevertheless, one (18) found no significant change.

Studies about the neuropsychological and behavioral characteristics of patients with $\mathrm{SH}$ reported significant deficiencies in the abilities related to memory (12) and logical memory (13). A reduction was observed in the total memory coefficient, but it was not significant (13).

The battery used in our pilot project comprised cognitive tests (WAIS-R vocabulary), visuospatial and perceptive-motor tests (Rey's complex figure), and the Buschke's selective reminding procedure. No significant conclusion was reached regarding the results of the tests in the pilot project, because of the reduced number of patients studied $(n=5)$. The need for better assessing the attention deficit and mainly the memory deficit was evidenced by comparing the tests used in the battery of the pilot project, which only showed a change, but did not guarantee a significant difference. Aiming at greater comprehensiveness, the Warrington's Recognition Memory Test for Words and Faces was included for a more accurate evaluation of visual memory and attention.

Previous clinical studies about $\mathrm{SH}$ reported several degrees of change in the affective and cognitive function (12), and such differences may be due to the designs of the studies and mainly to the characteristics of the controls and patients selected. In the literature, the samples were selected from population studies, from patients who were already being followed up on an Endocrinology outpatient clinic, and from patients previously treated for hyperthyroidism. Those methodological differences rendered the assessment difficult to differentiate whether the neuropsychological findings derived from $\mathrm{SH}$ or from nonspecific findings reported by the patients. Other authors related the changes rather to the duration of disease than to TSH levels (17). Therefore, we chose to form a homogeneous sample with 65 recently diagnosed patients followed up in the Endocrinology outpatient clinic. Because age may cause alterations in the cognitive function (13), we selected patients aged from 18 to 65 years, thereby avoiding the insertion of confounding factors, since the incidence of neuropsychological changes is higher outside that age group. Thus, our study differs from others $(15,16)$, in which the patients were older than 65 years.

Another issue was the composition of the control group. In two studies, the control group comprised patients with thyroid disease $(12,16)$. Two others $(11,14)$ used healthy controls, and another (13) used the parameters of the Italian population. We used a homogeneous control group from the same hospital environment, meeting the same inclusion criteria, which had neither thyroid disease nor antithyroid antibodies. We believe that the patients and controls should be as similar as possible, the only difference between them being the presence or absence of thyroid disease.

Regarding the neuropsychological assessment of the studies comparing the groups with and without thyroid disease, ours obtained results similar to those obtained by Bono et al. (13), that is, no difference was observed between the euthyroid group and that of patients. Those authors found small alterations associated with age, with no relation between the complaints and the cognitive alterations. On the other hand, Pollock et al. (14) reported cognitive deficits in 9 out of 15 measurements performed. Those differences may be related to the samples used in different studies. The cognitive deficits found in patients with $\mathrm{SH}$ in other studies $(11,12)$ may be due to the previous knowledge of the patients' disease, because they were selected when assessed for the treatment of goiter.

\section{CONCLUSION}

No difference was observed in the performance of the neuropsychological tests between both groups in regard to the functions studied.

\section{REFERENCES}

1. Wang C, Crapo LM. The epidemiology of thyroid disease and implications for screening. Endocrinol Metab Clin North Am 1997;26(1): 189-218.

2. Awad AG. The thyroid and the mind and emotions/thyroid dysfunction and mental disorders. Available at: <http:// www.thyroid.ca /Articles/EngE10F.html>. Accessed in November 2002.

3. Stern TA, Simon H, Etkin MJ, et al. What is hypothyroidism? Available at: <http://my.webmd.com/content/article/1680. 51476>. Accessed in September 2001.

4. Laureno R. Neurologic manifestation of thyroid disease. Endocrinologist 1996;6:467-73.

5. Dugbartey AT. Neurocognitive aspects of hypothyroidism. Arch Int Med 1998;158:1413-8.

6. Haggerty $\mathrm{JJ} J \mathrm{~J}$, Evans $\mathrm{DL}$, Prange AJ. Organic brain syndrome associated with marginal hypothyroidism. Am J Psychiatry 1986;143(6):785-6.

7. Haggerty JJ, Prange AJ. Borderline hypothyroidism and depression. Annu Rev Med 1995;46:37-46.

8. Whybrow PC, Prange AJ Jr, Treadway CR. Mental changes accompanying thyroid gland dysfunction. Arch Gen Psychiatry 1969;20:48-63.

9. Jain VK. A psychiatric study of hypothyrodism. Psychiatr Clin 1972;5:121-30. 
10. Asher R. Mycoedematous madness. Br Med J 1949;22:55562.

11. Monzani F, Guerra PD, Caraccio N, Pruneti CA, Pucci E, Luisi $M$, et al. Subclinical hypothyroidism: neurobehavioral features and beneficial effect of L-thyroxine treatment. Clin Investig 1993:71:367-71.

12. Baldini IM, Vita A, Massimo C, Amodei V, Carrisi M, Bravin S, et al. Psychopathological and cognitive features in subclinical hypothyroidism. Prog Neuropsychopharmacol Biol Psychiatry 1997;21(6):925-35.

13. Bono G, Fancellu R, Blandini F, Santoro G, Mauri M. Cognitive and affective status in mild hypothyroidism and interaction with L-thyroxine treatment. Acta Neurol Scand 2004; $110: 59-66$.

14. Pollock MA, Sturrock A, Marshall K, Davidson KM, Kelly CJG, McMahon $A D$, et al. Thyroxine treatment in patients with symptoms of hypothyroidism but thyroid function tests within the reference range; randomised double blind placebo controlled crossover trial. BMJ 2001;323:891-5.

15. Nyström E, Caidahl K, Fager G, Wikkelsö C, Lundberg PA, Lindstedt $\mathrm{G}$. A double-blind cross-over 12-month study of Lthyroxine treatment of women with 'subclinical' hypothyroidism. Clin Endocrinol 1998:29:63-76.
16. Jaeschke R, Guyatt G, Gerstein H, Patterson C, Molloy W, Cook $D$, et al. Does treatment with L-thyroxine influence health status in middle-age and older adults with subclinical hypothyroidism? J Gen Intern Med 1996;11(12):744-9.

17. Jensovsky J, Ruzicka E, Spackova N, Hejdukova B. Changes of event related potential and cognitive processes in patients with subclinical hypothyroidism after thyroxine treatment. Endocr Regul 2002;36:115-22.

18. Jorde $R$, Waterloo $K$, Storhaug $H$, Nyrnes A, Sundsfjord J, Jenssen TG. Neuropsychological function and symptoms in subjects with subclinical hypothyroidism and the effect of thyroxine treatment. J Clin Endocrinol Metab 2006;91(1):145-53.

\section{Endereço para correspondência:}

Cloyra Almeida

Secretaria do Servico de Endocrinologia - HUCFF/UFRJ

Av. Brigadeiro Trompowski s/n, $9^{\circ}$ andar, sala E 23

21941-590 Rio de Janeiro, RJ

E-mail: mleite@openlink.com.br 